\title{
L1 vs L2 writing: ESL graduate students' perceptions
}

Tony Silva

This paper reports on a classroom based study that explored ESL graduate students' perceptions about (1) differences between writing in their native language and writing in English and
(2) how these differences should be reflected in the practices of ESL writing teachers. Findings are illustrated with the students' own words.

\section{INTRODUCTION}

A student writes: "Writing is fun? Yes, if I write in my native language, but not if I write in English. As a Chinese graduate student, I have quite a good education in Chinese. So, for me, writing in Chinese is just as easy as talking. Sometimes I quite enjoyed it when I wrote a beautiful essay or letter. But writing in English is another story. I feel writing is so difficult that I would rather do an experiment than write an English essay. Usually, it takes me a long time to write an English essay even if it is a short one. What is so different? What is so difficult?" The questions that this student raises are essentially those that this paper will address.

One important aspect of understanding second language (L2) writing is knowing how it differs from first language (L1) writing. The most common way of studying these differences has been to observe and analyze students' behaviors and written texts. While such observation is necessary, interesting, and valuable, it is just as, if not more, important for ESL writing teachers to know how their students perceive the differences in writing in their first and second languages. The study reported on here examined these perceptions.

\section{LITERATURE REVIEW}

As mentioned above, the research on L1 vs ESL writing ${ }^{1}$ has been primarily observational in nature. One popular focus has been composing processes: Chelala (1981), Skibniewski (1986), Arndt (1987), Skibniewski \& Skibniewska (1988), Schiller (1989), and Moragne e Silva (1989) provide comprehensive accounts; Jones \& Tetroe (1987) deal specifically with planning; and Gaskill (1986) and 
Hall (1987/1990) address revising. Another point of interest has been written texts: Santiago (1970), Norment (1986), Indrasuta (1987/1988), and Lin (1989) analyze text structure; Cook (1988) examines paragraph structure; and Almeida (1984) and Indrasuta (1987/1988) focus on cohesion. DeJesus (1983/1984) and Cook (1988) looked for correlations between L1 and ESL writing ability.

This observational research literature, though it indicates broad similarities in L1 and ESL writing (i.e., in both cases writing is a complex and recursive intellectual process), suggests some interesting differences. The picture the research presents is one in which ESL composing processes seem generally more laborious than those in the L1. Planning requires more effort and generates material that is less detailed, developed and useful. Transcribing, i.e., going from thought to written text is also more difficult. And when reviewing, writers focus more on lexical and grammatical concerns and revise more, but less effectively.

The research also indicates a number of differences in written ESL texts. These texts tend to be shorter and less developed and to receive lower quality ratings. Their paragraphs are less unified. Working in the L2, ESL writers seem to have fewer cohesive resources and less control over those they possess. They use less figurative language. Their smaller L2 vocabularies result in less ability to recognize words' subtle nuances. Also, they make more errors overall. Finally, correlations between L1 and ESL writing ability were significant but moderate.

While the research described above is fairly extensive and generally informative, none of the studies focus primarily on ESL students' perceptions about differences in L1 and L2 writing. ${ }^{2}$ The study reported on in this paper is an attempt to fill this gap in the literature. Its primary focus is on ESL writers' perceptions of L1/L2 writing differences. In particular, it asks these writers to comment on (1) how writing in a second language is different from writing in their first-with regard to both strategic and textual factors, and (2) given these differences, what ESL composition teachers can do to best meet their students' needs.

\section{METHODS}

\section{Context}

The context for this study was a writing course for international graduate students taught by the researcher at a large public university in the USA. Earning a passing grade in this course was 
one way in which students could meet the university's graduate school writing requirement. The main work of the course was writing four papers: (1) a statement of purpose in support of a scholarship application to be judged by a panel of college faculty and administrators; (2) a description of the student's major field meant to interest high school seniors in the USA in his or her discipline; (3) a letter to the editor of the campus newspaper describing and offering solutions to a campus problem; and (4) an essay for the TESOL Quarterly readership describing their (the students') perceptions of the differences between writing in their first language and writing in English and offering suggestions, based on these differences, for how ESL writing teachers could best serve their students.

Each of these papers was completed in nine one-hour class sessions over a period of approximately three weeks. During this time the students engaged in a great deal of planning (focussing on aim/purpose, audience, and persona; generating ideas; and considering organizational options), wrote three complete drafts, and reviewed (read, evaluated, revised, and edited) their papers (as well as papers written in response to the same assignment by students who took the course in previous semesters) in terms of content, organization, vocabulary, grammar, and mechanics.

The final drafts of the fourth essay described above (the TESOL Quarterly essay) constituted the primary source of data for this study. (See Appendix A for the full text of this assignment.) Additional, contextualizing data were drawn from the subjects' responses to a questionnaire (an instrument developed in house to elicit basic demographic and educational background information) and from their results on a battery of common standardized measures (the relevant ones here being the Michigan Test of English Language Proficiency [MTELP]-a general ESL proficiency test-and a writing sample patterned after ETS' Test of Written English [TWE]) that were administered routinely during the first week of classes in all ESL courses at the university.

\section{Subjects}

The subjects for this study were the thirteen members of the class described above. Table 1 indicates that the subjects ranged in age from 24-49, with a mean of 29.6; included six women and seven men; came from seven different countries (China, Japan, Taiwan, Turkey, Brazil, Sri Lanka, and Tunisia); spoke six different native 
TABLE 1

Subject Demographics

\begin{tabular}{lllllllllllllllll}
\hline \hline Student & 1 & 2 & 3 & 4 & 5 & 6 & 7 & 8 & 9 & 10 & 11 & 12 & 13 & X \\
\hline Age & 29 & 49 & 29 & 28 & 29 & 24 & 26 & 28 & 26 & 27 & 25 & 33 & 32 & 29.6 \\
Sex & M & M & M & M & F & F & F & F & F & F & M & M & M \\
Origin & JA & CH & TA & BR & JA & TR & TN & TR & TA & SR & CH & CH & CH \\
L1 & JA & CH & CH & PO & JA & TR & AR & TR & CH & TM & CH & CH & CH \\
Time/USA \\
(months)
\end{tabular}

languages (Chinese, Japanese, Turkish, Arabic/French, Portuguese, and Tamil); had spent from one to 48 months in the USA, 15.2 months on the average; represented nine different fields (Agronomy, Food Science, Biochemistry, Biological Science, Civil Engineering, Consumer and Family Sciences, French Literature, Mechanical Engineering, and Physics); included seven doctoral and two master's students and four visiting scholars; had had from one to ten years of English instruction, with a mean of 6.3 years; and received (converted total) MTELP scores ranging from 56-86, with a mean of $73.7^{3}$ and writing sample ratings ranging from $2.5-4.5$, with a mean of 3.6. ${ }^{4}$ Unfortunately, no useful data on the subjects' attitudes toward or experience in writing in general was available for this study. 


\section{Data Analysis}

The background data on the subjects were compiled, coded, and charted; counts of responses were made and ranges and means were calculated where appropriate. With regard to the analysis of the subjects' written texts, the researcher read the papers closely and repeatedly and developed classification systems for the reported types of L1/L2 differences and suggestions for teachers through the interaction of his observations made while reading the texts and his relevant prior knowledge of the L1 and L2 writing literature.

The classification system developed for perceived differences in L1 and L2 writing included three major categories which each subsumed a number of minor categories. The first category, process, included references to planning (generating, goal setting, and organizing), writing (transcribing ideas into written text), and reviewing (reading, evaluating, and revising). The second category, rhetoric, subsumes references to audience, paragraphs, directness, cultural allusions, formality, style, organization, and introductions. The third category, language, includes references to sentences, phrases, vocabulary, and print code conventions (spelling and capitalization).

The classification system developed for subjects' suggestions for teachers has four main categories. The first, process, as in the difference classification system, includes references to planning, writing, and revising. The second, culture, subsumes references to culture in general, directness, and audience. The third major category, pedagogy, includes references to classroom concerns, writing assignments, and learning activities beyond the classroom. The final major category, language, subsumes references to L1 and L2 comparisons, spoken versus written form, grammar (morphosyntactic features), vocabulary, and print-code conventions.

To test the reliability of the text analyses-of consistently placing references into categories-two coders (the researcher and another experienced ESL professional with expertise in writing) independently analyzed the references in two randomly selected student texts. There was $100 \%$ agreement on the classification of references for both differences and suggestions. 


\section{RESPONSES}

In this section, the subjects' perceptions about the differences in writing in their first and second languages and their suggestions, based on these perceived differences, for what ESL writing teachers can do to help students like them will be described and illustrated.

Perceived Differences

TABLE 2

Perceived Differences

\begin{tabular}{|c|c|c|c|c|c|c|c|c|c|c|c|c|c|c|}
\hline Student & 1 & 2 & 3 & 4 & 5 & 6 & 7 & 8 & 9 & 10 & 11 & 12 & 13 & $\mathrm{~T}$ \\
\hline PROCESS & & & & & & & & & & & & & & \\
\hline Planning & & $\mathrm{x}$ & $\mathbf{x}$ & & & $\mathrm{x}$ & $x$ & & & & & $\mathrm{x}$ & $\mathrm{x}$ & 6 \\
\hline Writing & & $\mathbf{x}$ & $x$ & & & $\mathbf{x}$ & $\mathrm{x}$ & $\mathrm{x}$ & & $\mathbf{x}$ & & $\mathbf{x}$ & $\mathrm{x}$ & 8 \\
\hline Reviewing & $\mathbf{x}$ & & $\mathbf{x}$ & & & & $\mathbf{x}$ & & & $\mathbf{x}$ & & & & 4 \\
\hline RHETORIC & & & & & & & & & & & & & & \\
\hline Audience & & & & & $\mathbf{x}$ & & & $\mathrm{x}$ & & & $\mathbf{x}$ & & & 3 \\
\hline Paragraphs & & & $\mathbf{x}$ & & & & & & & $x$ & & & $\mathbf{x}$ & 3 \\
\hline Directness & $\mathrm{x}$ & & & & $\mathrm{x}$ & & & & & & & & & 2 \\
\hline $\begin{array}{l}\text { Cultural } \\
\text { Allusions }\end{array}$ & & $\mathrm{x}$ & & & & & & & & & & $x$ & & 2 \\
\hline Formality & & & & & & $\mathbf{x}$ & & $\mathrm{x}$ & & & & & & 2 \\
\hline Style & & & & & & & $\mathrm{x}$ & & & & & & & 1 \\
\hline Organization & & & $\mathbf{x}$ & & & & & & & & & & & 1 \\
\hline Introduction & & & & & & & & & & & & & & 1 \\
\hline LANGUAGE & & & & & & & & & & & & & & \\
\hline Sentences & $x$ & & & $\mathrm{x}$ & & $\mathbf{x}$ & & & $x$ & $\mathbf{x}$ & & & $\mathbf{x}$ & 6 \\
\hline Pbrases & & & & $\mathrm{x}$ & & $\mathbf{x}$ & $\mathrm{x}$ & & $\mathrm{x}$ & & & & $x$ & 5 \\
\hline Vocabulary & & $x$ & $x$ & $\mathrm{x}$ & $x$ & $\mathbf{x}$ & & $x$ & $\mathrm{x}$ & $x$ & $x$ & $x$ & & 10 \\
\hline Print Code & & & & & & $\mathrm{x}$ & $\mathrm{x}$ & & & $x$ & & & & 3 \\
\hline TOTAL & 4 & 4 & 6 & 3 & 3 & 7 & 6 & 4 & 3 & 6 & 2 & 4 & 5 & 57 \\
\hline
\end{tabular}

\section{Process}

A number of differences between $\mathrm{L} 1$ and $\mathrm{L} 2$ planning were reported. S2 mentioned needing more time to understand an L2 writing assignment. S3 reported that it was difficult for him to 
adjust his L1 planning style-in which proverbs were the first thing to come into his mind-to his L2 writing. S7 noted a difference in focus in her L1 and L2 planning:

When I plan for a French composition, I focus basically on the topic and style, which is the way to express my ideas very well; while, when I plan in English, I just translate from French to English, and I care much about choosing the right words and appropriate expressions.

S12 noted a distinction that is a function of writing for an unfamiliar audience:

...when I write an English essay, the readers will be foreigners and I don't know much about them. So, I always have a hard time deciding what should be written and what should not and which way is proper to express my idea when I compose an English essay.

Finally, four subjects (S2, S6, S7, S13) indicated that in planning an L2 composition, they did their thinking primarily in the L1.

The data also indicate some differences in writing (defined here as going from thought to written text) in $\mathrm{L} 1$ and $\mathrm{L} 2$. The comments of eight subjects (S2, S3, S6, S7, S8, S10, S12, S13) present a picture of L2 writing in which L2 linguistic limitations (especially vocabulary and grammar) and/or $\mathrm{L} 1$ interference make $\mathrm{L} 2$ writing more form focused and time consuming and less fluent and make the texts produced less sophisticated (simpler words, shorter sentences) and less expressive of the writer's thoughts and intentions. The following quotations capture well the subjects' thoughts on this matter.

S2: When I write it, I have to use most simple words if they can be used, and use sentences that are as short as possible. Sometimes, I have to avoid some unfamiliar words, which are better for the article. Therefore, the article becomes wordy and powerless.

S7: ...when I'm writing in French, I use long sentences and very complex phrase structure; while in English, I try to use very short and simple sentences. But, most of the time, I can't find the appropriate words. Once I wrote a whole page in English, 
and then deleted because I found myself repeating the same idea many times.

S12: When I write in Chinese I never think about my grammar. My sentences, just like the ink in my pen, come out naturally. But when writing in English, usually, I need to think of the sentences in Chinese first, and then I translate them into English according to English grammar. This is particularly true when I write a long sentence or express a complicated situation. Even doing it in this way sometimes I still have trouble making my meaning clear. It seems that the grammar is the only tool that I can use in writing English essays. I wish that I could totally forget the grammar when I am writing in English as I do in Chinese.

Four subjects commented on L1/L2 differences in reviewing. S1 noted that when reviewing in the L2, he spends more time on spelling and grammar and, consequently, less on organization than when writing in his L1. S3 reported that differences in the connotations of words and expressions in the L1 and L2 made revising in the L2 very difficult. S7 said that her considerations regarding reviewing were quite different in $\mathrm{L} 1$ and L2. In her L1 she would focus primarily on style and text structure; in her L2, vocabulary and word order would be her main considerations. Finally, the following comment by S10, who had formal writing instruction in English, but none in her L1, is in counterpoint to the experience described by the first three subjects:

...I've different experience in reviewing an article written by me in English and Tamil. I make a lot of changes in English when I revise. I try to make the sentences connected or change to fancier words or try to make the whole sentence more attractive or fascinating. In my language, I don't have much room to make these kinds of changes.

\section{Rhetoric}

The subjects also reported differences between L1 and L2 writing with regard to rhetorical concerns. Three subjects dealt with the differential effects of writing for L1 and L2 audiences. S8 felt it was necessary for her to share some common understandings with her L2 audience in order to provide appropriate and effective examples. S11 believed he had fewer options with regard to choice and 
presentation of material when writing for the unfamiliar audience. And S5 dealt with differing expectations of L1 and L2 audiences with regard to types of appeals and evidence:

...I have to recognize the difference between audiences to write effectively. For example, when I write an application letter to the scholarship committee as an English assignment, I wrote "I would be a successful student." In Japan I could never say such a thing. To appeal directly has almost an opposite effect.

Differences in L1 and L2 paragraph structure were addressed by three subjects. S10 reported that she wrote longer paragraphs in her L1 than in her L2. The other two subjects both talked about the distinction between English and Chinese paragraphs. S13 contrasted the two, noting that whereas English paragraphs began with a topic sentence and moved from effect to cause, Chinese paragraphs had their topic sentences at the end and moved from cause to effect. S3 characterized English paragraphs as deductive rational arguments, supported by statistical data and accounts of personal life experience; Chinese paragraphs were seen as more inductive, with statements typically supported by citations of historical events.

Two subjects, the two Japanese speakers, commented on the issue of directness. S1 stated simply that "American people prefer more straight-forward expression. On the other hand, Japanese like indirect and vague expression." S5 illustrates this statement a bit:

...there are few "roundabout ways" of expression in English or [else] I don't know them well. In Japan, direct expression is often thought to be impolite. When I have to express my opinion in English, I always hesitate at this point. For example, I avoid writing a conclusion. When I would like to express that "I don't know how to use it," I would write in Japanese that "I'm not sure how to use it or it seems difficult for me to know how to use it."

Two subjects, both native speakers of Chinese, recognized the difficulties inherent in trying to use references tied to their L1 culture in their L2 writing. S12 explains and illustrates the problem:

In the Chinese language there are a lot of parables and idioms, which are referred to in essays quite frequently. Most 
Chinese like to use an idiom to describe a complicated situation in their essays. So am I. But some Chinese idioms are quite difficult to translate into English...For example when I want say a person superficially does one thing, but, in effect he/she intends to do another thing, in Chinese I can use a saying, "Xiangzhuang thinks Peigong while playing sword," to express it. This reference came from an ancient Chinese story. The story said a person, Xiangzhuang, invited Peigong to play swords together, in effect, his purpose was killing him rather than playing a game. If I were to write this reference in my English essay, maybe few Americans could understand it.

S2 provides an additional example:

The Chinese idiom "there are ready-made bamboos in someone's chest" may surprise foreigners. But its real meaning is "someone has a well-thought-out plan." Perhaps an American can understand a foreigner's speaking, but it is not good English.

The issue of level of formality was raised by two subjects, both native speakers of Turkish. S8 reported that because of her desire to show respect to foreigners (her L2 readers), she wrote more formally in her L2 than in her L1. S6 felt a bit unsure of her ability to gauge the appropriate level of formality in her L2 writing:

...I often hesitate about my writing, whether it is formal enough or not, what people think about it, whether it will be polite or not, etc. But, if I write in Turkish, I know which expression is polite and which one is not...

One subject (S7) considered differences in style, in a general sense:

A French text is different from an English one. A French text has to be very rhetorical and very elaborated in style. It has to contain metaphors and very expressive sentences. But an English text doesn't need, in my opinion, all this artificial eloquence.

Another subject (S3) discussed, albeit incompletely, the distinctive pattern of a Chinese essay: 
...the standard organization of Chinese writing is composed of four paragraphs. Each part has its own function. The first paragraph usually defines the topic and clarifies it. The second paragraph illustrates a positive example (usually a successful story) to support main idea in first paragraph. The third paragraph illustrates a negative example to warn the reader what the possible disadvantage will be. Finally, what does the conclusion do." [The writer ended his description here.]

S1 comments on the features of and reactions to the introductions produced by some native speakers of Japanese:

Some Japanese who are not familiar with business writing have a tendency to write unnecessarily long and formalized introductory remarks, in which they humble themselves and state as often as they can that they are not able to write their essay and thank as many people as they can. Japanese simply go through the introductory remarks, but this confuses American people because they question why this author is writing this essay if he thinks he is not able to write the essay.

The brief introductory remarks of S5 (another native speakers of Japanese) support his claim: "According to our English teacher's request, I have written a short essay about the difference between writing in English and Japanese from my experience. I hope that from even my insufficient experience I can give you some information."

\section{Language}

The subjects also reported numerous differences with regard to language. Six subjects commented on differences between $\mathrm{L} 1$ and L2 sentences. S1 and S4 reported differences in word order, with S4 noting that word order was more flexible in his L1. S6 described differences in terms of the order of subject, verb, and object. S9 talked about sequencing tenses in complex sentences, noting that this was not necessary in her L1. S10 said her L1 sentences were shorter than those she wrote in L2 due to the relative absence of subordinates in the written form of her L1. And S13 reported differences in the position of adverbial modifiers and subordinate clauses, English offering more options than his L1.

Five subjects mentioned L1/L2 differences at the phrasal level-phrasal referring here basically to morphological and 
collocation matters. S4 noted difficulties with phrasal verbs in English:

Another difficulty for me in writing and even in speaking and listening is the verbs. In English they have prepositions like: on, out, for, etc, that can change completely the common meaning of these verbs, and this confuses me a lot. As an example, I can list: try on, look out, go for, and many others. Hence, I prefer to use the verbs that are originated from Latin, which contain identical nuclei of those in Portuguese, as a result, occasionally, I select the most peculiar ones.

S6 talks generally about grammatical problems in English related to L1/L2 differences. S7 deals with L2 writing problems related to the common use of compound nouns, short form possessives ('s), and phrasal verbs in English. S9 discusses problems with the use of L2 idiomatic expressions. And S13 refers to some confusion related to exceptional cases in English (e.g., work available-noun plus adjective word order) and to differences in directional collocations (e.g., North-east in English is east-north in Chinese).

Ten of the thirteen subjects (S2, S3, S4, S5, S6, S8, S9, S10, S11, S12) commented explicitly and often at length on L1/L2 differences in the use of words. Their common view of this seems to be that the limited nature of their L2 vocabularies makes them unable to express their ideas, feelings, and perceptions accurately and precisely. What is missing in the L2 is the ability to manipulate lexical nuance and connotation. In addition, it was commonly felt that bilingual dictionaries were of little help in this regard.

Some excerpts from the subjects' texts on the issue of vocabulary provide the flavor of the comments made.

S2: I think my ideas are okay, but I can not express them easily. I have to give up some good ideas for I can not find the available words. Even the meaning might be ambiguous and confused since I am not sure if the expressions are right.

S3: How to use appropriate words is another problem in writing an English article. Although we could solve translated problems by referring to a Chinese English dictionary or other resources, the deeper meaning the words used are usually neglected. For example: "humble" house could mean positive or negative in English, but it is negative in Chinese. "Sophistication" could be used in both positive and negative 
ways in English but most Chinese-English dictionaries misrepresent this meaning as a negative one. Thus, the cultural differences raise a problem that is hard to solve.

S11: Lacking enough vocabulary, I feel it is difficult to find the right word to describe a complex system in English. For instance, it is very easy for me to use four different words to describe the difference in strength a person uses to push a door in Chinese; while I only know two words to describe the same thing in English, hard and harder. As a result, I try to simplify the phenomenon I am writing [about]. When I have to describe the subtle difference between things, I feel uncomfortable.

S12: Vocabulary is also a limitation in my English writing. I don't know very many English words as I do in Chinese. I can recognized a very small difference between synonyms. When I write texts in Chinese, I can chose different words to express same meaning, depending on my feeling and mood. So I can chose the right words to express my ideas accurately. But I cannot do that well in English. For example, if I am saying someone is clever, I have several choices to express "clever" in Chinese, such as "jizhi," "ninghou," and "jiaohua," depending on my mood. The first one has a positive meaning, the second is neutral, and the third is negative. But in English I cannot tell the difference between "clever," "wise," and "smart."

L1/L2 differences in print code conventions (i.e., spelling, punctuation, capitalization) were referred to by three subjects. One (S6) noted that spelling was more problematic for her in English than in her L1. The other two dealt with capitalization. S7 reported that her $\mathrm{L} 1$ did not use capitals in language names or the adjectives derived from them; S10 said her L1 used no capitalization at all.

\section{Suggestions}

\section{Process}

Four subjects provided suggestions related to composing processes. Three addressed planning. S1 suggested that teachers spend more time on planning organization (since, he felt, students can pay little attention to organization while reviewing) and use flow charts for such planning. S4 and S13 also addressed planning, 
TABLE 3

Suggestions

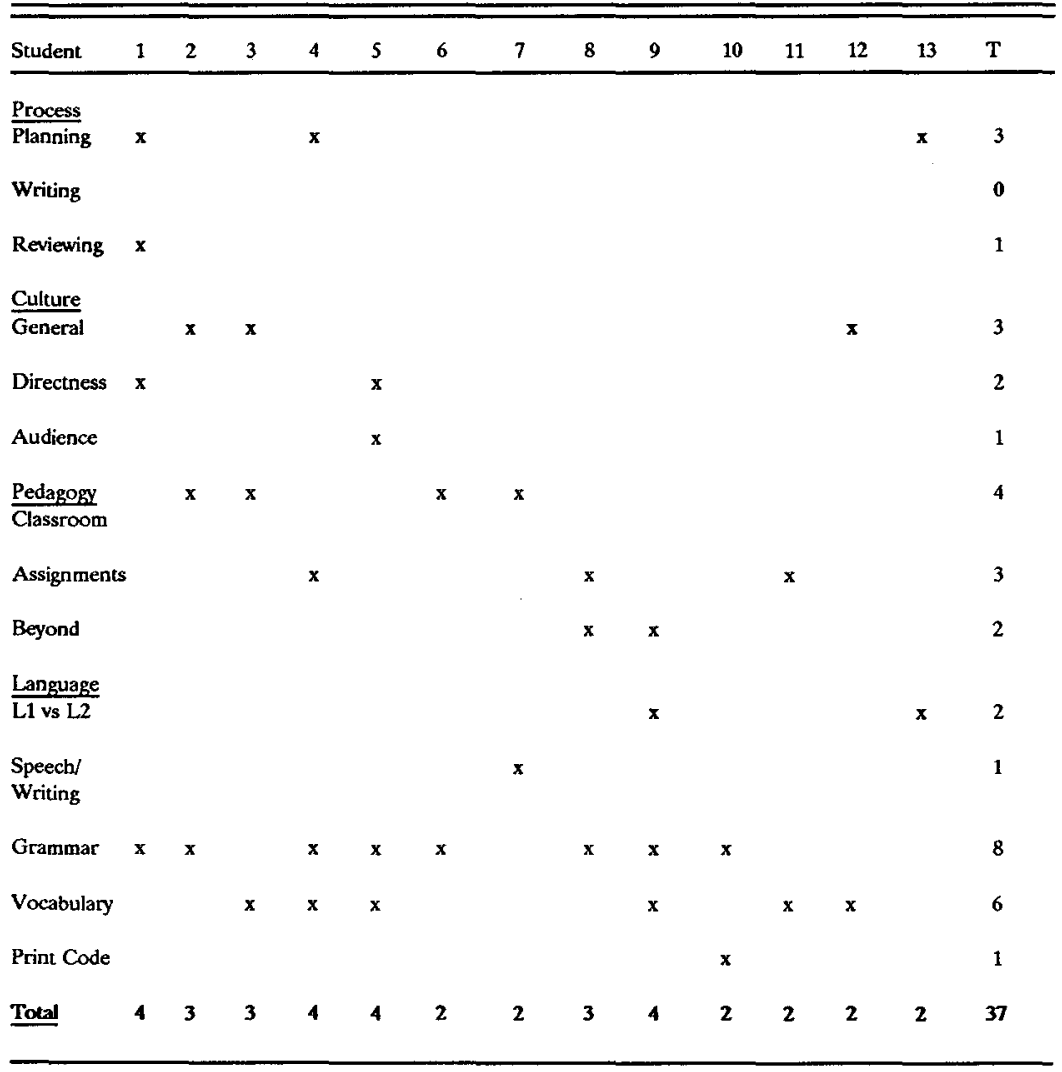

but in a less positive manner. S4 said that "...we shouldn't spend more energy on generating ideas to write than we do on the writing itself." Similarly, S13 felt that the main problem in learning to write in English is a linguistic one, and, consequently, stated that

Therefore we hope that our teachers can teach us how to deal with this problem instead of how to arrange content or how to attract readers because most of us graduated from a university or college, and should have taken one or more composition courses in our own language in our own country...

None of the subjects dealt with writing, but one (S1) discussed reviewing, suggesting that it should be divided into two parts: one focusing on organization; the other, on grammar and spelling. 


\section{Culture}

Three subjects (S2, S3, S12), all native speakers of Chinese, suggested that ESL writing teachers need to spend more time talking about the L2 culture-history, customs, habits, literature. Two subjects, both native speakers of Japanese comment on dealing with the notion of directness. S1 states that

...ESL teachers should explain the culture of the United States which allows people to state freely their opinions regardless of their age and gender as well as mere writing skills in order to liberate Japanese students from indirect and vague expression.

S5 felt that examining native speakers' texts she could learn about Americans' notion of politeness and find out when and where it manifests itself in their writing. S5 also suggested that she could learn about American audiences' expectations in general by getting face to face feedback and criticism of her L2 writing from American readers (in addition to that which she received from her teacher).

\section{Pedagogy}

Four subjects had somewhat general suggestions for what should be done in the classroom. S2 says that the teacher should speak clearly and loudly and repeat often (perhaps a reflection of this subject's difficulties in L2 listening comprehension), pay attention to each individual student, raise students' interest and maintain a lively classroom atmosphere in which students follow the teacher actively. S3 felt that the teacher should use audiovisual materials (especially video and audiotape) to expose students to the "thought and logic of English." S6 stated that the teacher should create an atmosphere of encouragement to help students do their best and learn to enjoy writing in English. S7 wanted the instructor to get students to generate options with regard to writing strategies.

Three subjects had suggestions regarding writing assignments. S4 said students should be asked to write papers that exercise their writing skills and vocabularies. S8 felt that the teacher should specify how students are to approach a particular topic and what points need to be emphasized. S11 stated that topics should be assigned and material provided so that students can focus on the writing process itself. Two subjects had ideas about learning activities beyond the classroom. S8 and S9 urged that teachers suggest opportunities for focused L2 listening and reading, e.g., TV shows, public talks, magazine articles, books. 


\section{Language}

With regard to language, two subjects $(\mathrm{S} 9, \mathrm{~S} 13)$ felt that teachers should be aware of the main differences in linguistic structure between English and their students' first languages and build a consideration of these differences into their courses. One subject (S7) suggested that teachers address the issue of spoken versus written English, providing their students with a list of common expressions in both the spoken and written forms.

Eight subjects made suggestions regarding the treatment of grammar. S8 and S9 felt a need for general instruction in grammar. S2 and S6 focused on the necessity for teacher correction and analysis of grammatical errors. Two others suggested an emphasis on particular grammatical phenomena: phrasal verbs (S4) and sentence formation and subordination (S10). Finally, two subjects, the Japanese, urged that while grammar should be addressed, it should not overshadow other important concerns. S1, concerned with appropriateness, said that

...the ESL teacher had better spend more time instructing Japanese students to avoid the expressions which are grammatically correct but not proper as English expression than to instruct English grammar since they (the Japanese students) know much about English grammar.

S5, emphasizing the importance of culture, stated that

When I write in English, there are many problems such as the use of prepositions other than the former examples. But the most important point is to get across my thoughts to other people, and that could be possible even if the use of prepositions or spelling of words are a little wrong. I believe that to learn a foreign language is to know another culture. So I hope that those who teach English composition will not only pay much more attention to correct grammar and to good organization, but also to teaching how natives think when they write the same things.

Six subjects had suggestions regarding vocabulary. Three called for some sort of classroom treatment: S3, for a discussion of word connotations; $\mathrm{S4}$, for a provision of a list of common connecting words; and S12, for exercises to enhance precision in word choice. The other three all urged that students should read more (books, magazines, etc.) and more widely in order to learn about words' 
connotations (S5), increase the size of their vocabularies (S9), and to develop the ability to describe subtle differences between objects (S11). Finally, one subject suggested that teachers review and analyze problematic sample texts to focus attention on the use of conventions.

\section{DISCUSSION}

The findings of this study can be summarized as brief responses to the research questions posed earlier:

1. In what ways did the subjects perceive L2 writing to be different from L1 writing?

The perceived differences reported were numerous (a total of 57 or more than four per subject on the average) and varied (falling into fifteen different classifications). Furthermore, there were substantial numbers of references in each major category: process $(18 / 32 \%)$, rhetoric $(15 / 26 \%)$, and language (24/42\%), with linguistic differences the most commonly cited. Especially salient were the areas of planning, writing, grammar (sentences and phrases), and vocabulary.

2. What suggestions did the subjects have regarding how ESL writing teachers could best help their students?

The suggestions offered here were also numerous (a total of 37 or nearly three per subject) and varied (of 13 different types). There were appreciable numbers of suggestions in each major category: process $(4 / 11 \%)$, culture $(6 / 16 \%)$, pedagogy $(9 / 24 \%)$, and language (18/49\%). And again linguistic concerns clearly predominated. Especially salient here were suggestions regarding grammar and vocabulary.

The results of this study would seem to suggest that those who teach and design courses for ESL graduate student writers might expect that their students will bring some fairly strongly held and well developed ideas about writing and writing instruction to class with them; it seems very unlikely that they will be tabulae rasae with regard to these concerns. In addition, while the research comparing L1 and L2 writing (as well as research in ESL writing in general) has tended recently toward a focus on writing processes, these subjects, despite spending a semester in a writing course that was clearly process oriented, tended to focus primarily on textual or product matters, especially on grammatical and lexical concerns. 
This could be seen as a healthy reminder that a discipline's theoretical mood swings may not necessarily reflect or coincide with the priorities of the individuals it serves.

\section{IMPLICATIONS}

The study has implications for theory, research and practice. With regard to theory, the study provides data to balance that from observational studies of differences in L1 and L2 writing. In a broader sense, it can be seen as contributing to the understanding of the perceptual dimension of L2 writing and writing instruction. In terms of research, the study has developed a rudimentary but viable set of procedures and tools for eliciting, categorizing, and analyzing L2 writers' perceptions about L2 writing and writing instruction. Finally, with regard to practice, the study's findings provide teachers with some tentative notions about what their students might be thinking with regard to what is going on in their writing classes. All of this is not to suggest that teachers should not trust their observations of students' behaviors; nor does it mean that teachers should necessarily implement student suggestions regarding instruction. It does indicate, however, that teachers need to be aware of and sensitive to their students' perceptions about writing and expectations regarding instruction so that they can make informed decisions about curriculum and pedagogy and develop and teach courses that support and encourage, rather than alienate their students.

\section{NOTES}

1. The research reported on here has been limited to studies involving adult subjects (from high school seniors to postgraduates, but primarily college students) producing texts in both English and their first language. An observation: In working with this research, it is difficult not to notice that much of it is not highly visible. Of the seventeen reports of research cited: nine are unpublished doctoral dissertations; one is an ERIC Document; and only seven are published articles-and four of these are in sources that are rather difficult to access. In my view, this reflects a problem endemic to scholarship in ESL writing, i.e., the recent surge of interest in ESL writing has not been accompanied by a corresponding increase in viable outlets for the publication of ESL writing scholarship. As a result, important, high quality work in this area is 
dying on the vine. Consequently, progress toward a better understanding of ESL writing and writing instruction is being impeded.

2. Some of these studies did, however touch tangentially on subjects perceptions of L1/L2 writing differences--notably Chelala (1981), Hall (1987), and Lin (1989). Generally speaking, subjects perceived greater difficulty with vocabulary, grammar, and spelling while writing in English.

3. According to the MTELP score interpretation guide, a score of 73.7, which fall into its 65-79 category, indicates that students "May take up to $1 / 2$ the normal academic load plus at least two semesters of courses (6 hrs. week) in English as a second language" (English Language Institute, University of Michigan 1977, p. 12).

4. A score of 3.6 falls between a three and a four on the TWE scoring guide. A three "Demonstrates some developing competence in writing, but it remains flawed on either the rhetorical or syntactic level, or both." A four "Demonstrates minimal competence in writing on both rhetorical and syntactic level" (Educational Testing Service 1989, p. 26).

\section{THE AUTHOR}

Tony Silva is an assistant professor of ESL in the English Department at Purdue University where he teaches ESL and TESL courses and coordinates the ESL writing program. He also co-edits (with Ilona Leki) the Journal of Second Language Writing.

\section{REFERENCES}

Chelala, S. (1981). The composing processes of two Spanish speakers and the coherence of their texts. Dissertation Abstracts International, 42(6), 2541A.

Cook, M. (1988). The validity of the contrastive rhetoric hypothesis as it relates to Spanish-speaking advanced ESL students. Dissertation Abstracts International, 49(9), 2567A. 
DeJesus, S. (1983). The relationship between Spanish and English writing proficiency among college freshmen in Puerto Rico. Dissertation Abstracts International, 44(3), 692A.

DeJesus, S. (1984). Predictors of English writing performance of native Spanish speaking college freshmen. ERIC Document Service No. ED 256184.

Educational Testing Service. (1989). Test of Written English guide. Princeton, NJ: Author.

English Language Institute, University of Michigan. (1977). Manual for the Michigan Test of English Language Proficiency. Ann Arbor, MI: Author.

Gaskill, W. (1986). Revising in Spanish and English as a second language: A process oriented study of composition. Dissertation Abstracts International, 47(10), 3747A.

Hall, C. (1987). Revision strategies in L1 and L2 writing tasks: A case study. Dissertation Abstracts International, 48(5), 1187A.

Hall, C. (1990). Managing the complexity of revising across languages. TESOL Quarterly, 24(1), 43-60.

Indrasuta, C. (1987). A comparison of the written compositions of American and Thai students. Dissertation Abstracts International, 48(7), 1681A.

Indrasuta, C. (1988). Narrative styles in the writing of Thai and American students. In A. Purves (Ed.), Writing across languages and cultures: Issues in contrastive rhetoric (pp. 206-226). Newbury Park, CA: Sage.

Jones, S. \& Tetroe, J. (1987). Composing in a second language. In A. Matsuhashi (Ed.), Writing in real time: Modelling production processes (pp. 34-57). New York: Longman.

Lin, C. (1989). The structures of English and Chinese narratives written by college students in Taiwan. Dissertation Abstracts International, 50(7), 2036A.

Moragne e Silva, M. (1989). A study of composing in a first and second language. Texas Papers in Foreign Language Education, 1(2), 132-151.

Norment, N. (1986). Organizational structures of Chinese subjects writing in Chinese and ESL. Journal of the Chinese Language Teachers' Association, 21(3), 49-72.

Santiago, R. (1970). A contrastive analysis of some rhetorical aspects in the writing in Spanish and English of Spanishspeaking college students in Puerto Rico. Dissertation Abstracts International, 31(12), 6368A. 
Schiller, J. (1989). Writing in L1-writing in L2. Case studies of the composing processes of five adult Arabic speaking ESL writers. Dissertation Abstracts International, 50(9), 2883A.

Skibniewski, L. (1988). The writing processes of advanced foreign language learners in their native and foreign languages: Evidence from thinking aloud and behavior protocols. Studia Anglica Posnaniensia, 21, 177-186.

Skibniewski, L. \& Skibniewska, M. (1986). Experimental study: The writing processes of intermediate/advanced foreign language learners in their foreign and native languages. Studia Anglica Posnaniensia, 19, 142-163.

\section{APPENDIX A}

\section{TESOL Quarterly Essay Assignment}

The editor of TESOL Quarterly, a journal for ESL professionals, has asked your instructor to edit a special issue of the journal which will address writing in English as a second language. Your instructor has decided not to solicit papers from the "experts" in this area, but rather, to ask you to offer your views on the subject in a series of short essays. Each essay (500-750 words) should address two basic questions: (1) How is the experience of writing in English different from that of writing in your native language? and (2) What do ESL instructors need to do to best help students like yourself to improve their writing. In responding to the first question, address differences both in your writing processes (e.g., planning, writing, revising) and your written texts (with regard to both content and form-organization, paragraphs, sentences, words, conventions). In your response to the second question, suggest instructional content, contexts, approaches, methods, and/or techniques that you feel would be most appropriate. Your response to the first question should provide the basis for your response to the second. Please note that the readers of TESOL Quarterly will not expect you to be an authority on linguistics, language learning, writing, or education. What they will expect are your own personal views and insights. Therefore, the use of examples and illustrations from your personal experiences in first and second language writing is essential. Your readers will probably not be very interested in papers that describe what we do in this course or in papers that focus primarily on a comparison of the linguistic structures of English and your native language. 